\title{
Copper-alloyed spinel black oxides and tandem-structured solar absorbing layers for high- temperature concentrating solar power systems
}

Tae Kyoung Kim ${ }^{\mathrm{a}, \mathrm{b}}$, Bryan VanSaders ${ }^{\mathrm{a}, \mathrm{c}, \#}$, Elizabeth Caldwell ${ }^{\mathrm{a}, \mathrm{b}}$, Sunmi Shin ${ }^{\mathrm{a}, \mathrm{b}}$, Zhaowei Liu ${ }^{\mathrm{a}, \mathrm{c}}$, Sungho Jin ${ }^{\mathrm{a}, \mathrm{b}, *}$, Renkun Chen ${ }^{\mathrm{a}, \mathrm{b}, *}$

${ }^{a}$ Materials Science \& Engineering, University of California at San Diego, CA 92093, USA

${ }^{b}$ Mechanical and Aerospace Engineering, University of California at San Diego, CA 92093, USA

${ }^{c}$ Electrical \& Computer Engineering, University of California at San Diego, CA 92093, USA

*Co-corresponding authors: jin@ucsd.edu, rkchen@ucsd.edu

\# Present affiliation: University of Michigan, Ann Arbor, MI 48109, USA

\begin{abstract}
Although renewable solar power plants are rapidly proliferating, high cost and the intermittent availability of solar power are still significant barriers for its penetration into the energy grid system. Concentrating solar power (CSP) offers an attractive alternative due to its integration with cost-effective thermal energy storage systems. To further reduce the cost of CSP, it is imperative to operate the plants at higher temperatures for enhanced efficiency. One of the key components for next-generation high-temperature CSP is the solar absorbing coating materials. In this work, we have developed tandem-structured solar absorbing layers with $\mathrm{CuFeMnO}_{4}$ and $\mathrm{CuCr}_{2} \mathrm{O}_{4}$ black oxide nanoparticles (NPs). These tandem structures exhibited a remarkably high solar-to-thermal conversion efficiency, or figure of merit (FOM), of 0.903 , under the condition of $750{ }^{\circ} \mathrm{C}$ operating temperature and a solar concentration ratio of 1000 . More importantly, the coating showed unprecedented durability, as demonstrated from long-term isothermal annealing
\end{abstract}


at $750{ }^{\circ} \mathrm{C}$ in air as well as rapid thermal cycling between room temperature and $750{ }^{\circ} \mathrm{C}$. Our results suggest that the tandem black oxide coating is suitable to meet the stringent demand of next-generation high-temperature CSP systems. The coating materials synthesis, structures, optical as well as thermal properties will be discussed.

Keywords: spinel black oxide nanoparticles, solar absorbing coating, tandem structure, porous surface, concentrating solar power.

\section{Introduction}

Electricity generation is accomplished by various ways including conventional power plants based on coal, natural gas, nuclear, and hydroelectricity, as well as renewable power plants including geothermal, biomass, wind, solar photovoltaic (PV) cells, and concentrating solar power (CSP) plants [1-5]. In 2012, electricity generation from the renewable sources in US amounted to $\sim 13 \%$ and it is anticipated to grow up to $18 \%$ in 2040 according to the projection of US Energy Information Administration (EIA) [6]. When estimating levelized cost of electricity (LCOE) in 2019, solar thermal electricity generation such as concentrating solar power (CSP) systems will still be around 3 times higher in LCOE than nuclear power plant and wind power plant [6]. To make CSP cost effective, US Department of Energy (DOE) targets to reduce the LCOE of CSP to $6 \notin / \mathrm{kWh}$ by 2020 which is $\sim 30 \%$ of the LCOE in $2010(21 \phi / \mathrm{kWh})$ [7]. To reach this target, it is necessary to develop advanced materials and structures to improve the performance and reduce the cost of CSP systems. Among various components of a CSP system, the solar absorber is a critically important element. Solar absorbers are typically made of metallic alloy tubes, inside which heat transfer fluids (HTFs) are heated up by the absorbed solar energy 
to generate high-pressure steam for power generation $[8,9]$. To enhance the solar absorbing capability, the tubes are usually coated with spectrally selective coating layers (for parabolic trough systems) or solar absorbing layers (for solar towers) [8-10]. To reach the DOE target, the following conditions on solar absorbers have to be achieved: HTF exit temperature $\geq 650{ }^{\circ} \mathrm{C}$, solar to thermal efficiency $\geq 90 \%$, and lifetime $\geq 10,000$ cycles [7]. However, solar absorber temperature of today's tower type CSP plant is around $550{ }^{\circ} \mathrm{C}$. As the efficiency of Carnot cycle type thermal device can be substantially increased by higher temperature operation, it is highly desirable to obtain a new solar absorber coating material that can withstand higher temperature exposure (such as $750{ }^{\circ} \mathrm{C}$ or higher) with long-term stability of structures and optical and thermal behavior.

Conventional solar receivers in solar tower plants are coated with a commercially available black paint named Pyromark. Pyromark-coated samples on Inconel 625 substrates showed degradation after $300 \mathrm{~h}$ isothermal annealing at $750^{\circ} \mathrm{C}$ in air, as reported by Sandia National Laboratories [11] . In order to increase the FOM, multi-layered solar absorbing layers have been developed using metal thin films with low IR emission [12]. However, this type of tandem structure with metal films can only be used in vacuum or under inert environment as in parabolic troughs, and is not suitable for high-temperature solar towers because it can be easily oxidized in air.

The scientific and engineering challenges of achieving simultaneous high solar absorptivity and high temperature durability lie in the difficulty of ensuring stability of structures and optical properties of metallic, ceramic or carbon based absorber materials at high operating temperatures (e.g. $750^{\circ} \mathrm{C}$ or higher) in air. Sturdy structures with nanoscale features can promote 
light trapping, diffuse and react optically well below their bulk melting point. Furthermore, multilayer thin film structures are prohibitively expensive to deposit on large surface area (hundreds of square meters per solar tower) in solar thermal plant structures. Also, the use of exotic nanopattering for improved light absorption or the use of nanophotonic structures will be too costly for solar thermal plant applications.

In this work, we overcome these challenges by adopting a number of novel strategies to demonstrate a new black oxide nanoparticle structure that is easy to produce by a simple spray coating process, exhibiting superior thermal stability and optical performance at high temperature. First, we synthesized spinel type $\left(\mathrm{AB}_{2} \mathrm{O}_{4}\right)$ copper-alloyed black oxide nanoparticles. Spinel metal oxides have been attractive to thermal applications because of their oxygen stoichiometry and crystal structure stability at high temperature [13-15]. Second, we utilized a two-layer tandem structure, consisting of a top layer of $\mathrm{Cu}-\mathrm{Fe}-\mathrm{Mn}$ oxide for absorption in the visible and near-infrared (IR) spectrum and a bottom layer of $\mathrm{Cu}-\mathrm{Cr}$ oxide responsible for nearIR absorption. Finally, we employed a highly scalable spray coating technique that created porous surfaces for efficient light trapping [9, 16-19]. By combining these novel features, as shown schematically in Figure 1(a), our two-layered black oxide samples exhibited a high FOM and high-temperature durability.

\section{Materials and methods}

\section{Synthesis of spinel Cu-alloyed metal oxide nanoparticles}

Two types of black oxide nanoparticles with spinel structure were synthesized hydrothermally utilizing the co-precipitation method modified from what was reported in our prior publication [20]. For the synthesis of copper chromates, $1 \mathrm{M}$ of copper chloride $\left(\mathrm{CuCl}_{2} \cdot 2 \mathrm{H}_{2} \mathrm{O}\right)$ aqueous 
solution was mixed uniformly with $1 \mathrm{M}$ of chromium chloride $\left(\mathrm{CrCl}_{3} \cdot 6 \mathrm{H}_{2} \mathrm{O}\right)$ aqueous solution with vigorous stirring for $5 \mathrm{~h}$, followed by co-precipitation into $\mathrm{Cu}-\mathrm{Cr}$ hydroxides by addition of $10 \mathrm{M} \mathrm{NaOH}$ into the solution. After mixing the co-precipitated hydroxides for $2 \mathrm{~h}$, hydrothermal synthesis was carried out in a $45 \mathrm{~mL}$ autoclave with a Teflon liner at $200{ }^{\circ} \mathrm{C}$ for $20 \mathrm{~h}$. During the post-treatment, centrifuged particles were dried with a freeze-dryer and finally crystallized at 550 ${ }^{\circ} \mathrm{C}$ for $5 \mathrm{~h}$ or $750{ }^{\circ} \mathrm{C}$ for $2 \mathrm{~h}$ in air. With this procedure, copper chromates with two different compositions were synthesized, namely $1: 1$ and $1: 2$ in atomic ratio of $\mathrm{Cu} / \mathrm{Cr}$.

In the case of the spinel $\mathrm{Cu}-\mathrm{Fe}-\mathrm{Mn}$ oxide, the overall synthesis procedure was the same as that of copper chromates, except that the precursor solutions were made of the mixture of $1 \mathrm{M}$ copper chromite $\left(\mathrm{CuCl}_{2} \cdot 2 \mathrm{H}_{2} \mathrm{O}\right), 1 \mathrm{M}$ iron chloride $\left(\mathrm{FeCl}_{3} \cdot 6 \mathrm{H}_{2} \mathrm{O}\right)$ and $1 \mathrm{M}$ manganese chloride $\left(\mathrm{MnCl}_{2} \cdot 4 \mathrm{H}_{2} \mathrm{O}\right)$ aqueous solution with different volumes depending on the atomic stoichiometry of $\mathrm{Cu}-\mathrm{Fe}-\mathrm{Mn}$ oxides. $\mathrm{Cu}-\mathrm{Fe}-\mathrm{Mn}$ nanoparticles with different compositions were synthesized, including 1:1:1, 0.5:0.5:2.0, 1.125:0.75:1.125, 2.0:0.5:0.5, and 0.5:2.0:0.5 in atomic ratio of $\mathrm{Cu} / \mathrm{Fe} / \mathrm{Mn}$.

\section{Fabrication of tandem-structured solar absorbing layers}

Using the synthesized $\mathrm{Cu}-\mathrm{Fe}-\mathrm{Mn}$ oxide and copper chromate nanoparticles, solar absorbing layers were fabricated with the following procedure. Resin (binder) solution of $7 \mathrm{wt} \%$ was made of methyl phenyl polysiloxane solution (SILIKOPHEN P80/X, Evonik) diluted with additional solvents (isobutanol, and xylene). In the case of dense layers, black oxide particles were dispersed in the binder solution with a weight ratio of $1 / 0.25$ (particles/resin) through slow ball milling for $24 \mathrm{~h}$, and then the mixed solution was spray-coated onto Inconel 625 substrates. The coated samples were dried at room temperature for one day, followed by curing and annealing 
via multi-step heat treatments in air: room temperature $-100{ }^{\circ} \mathrm{C}$ for $10 \mathrm{~min}, 250{ }^{\circ} \mathrm{C}$ for $2 \mathrm{~h}, 550$ ${ }^{\circ} \mathrm{C}$ for $3 \mathrm{~h}, 750{ }^{\circ} \mathrm{C}$ for $2 \mathrm{~h}$, and finally back to room temperature. Samples with $25 \mu \mathrm{m}$ thick coating layers could be obtained from these processes. The maximum annealing temperature $\left(750^{\circ} \mathrm{C}\right)$ was determined based on the target operation temperature of the solar absorber. Particle growth during the annealing process is expected to be suppressed due to the presence of the matrix material (spin-on glass).

To make the porous layers, we followed our prior approach of using sacrificial polymer beads [21]. In this process, both the black oxide nanoparticles and polymer beads (Soken Chemical \& Engineering) were dispersed into the binder solution with a weight ratio of 1.0/0.8/1.1 (particles/beads/binder resin) using a probe-type sonicator. We used two types of polymer beads, namely, cross-linked polystyrene beads with nominal size of $1.3 \mu \mathrm{m}(\mathrm{SX}-130 \mathrm{H})$ and acrylic beads of $400 \mathrm{~nm}$ (MP2701). The coating procedure for making the porous layer is identical as that for the dense layer. The porous coating layer with $\sim 5 \mu \mathrm{m}$ thickness could be fabricated on top of the dense coating layer to make 2-layered tandem structure or on the bare substrate of Inconel 625 as a single coating layer. Especially, two-layer solar absorbing samples fabricated with a porous top layer of $\mathrm{CuFeMnO}_{4}$ particles and a dense bottom layer of $\mathrm{CuCr}_{2} \mathrm{O}_{4}$ particles will be named $\mathrm{CuFeMnO}_{4}(\mathrm{PT}) / \mathrm{CuCr}_{2} \mathrm{O}_{4}(\mathrm{DB})$.

Figure 1(a) shows a schematic illustration of a 2-layered tandem structure fabricated from a porous top layer of $\mathrm{CuFeMnO}_{4}$ nanoparticles and a dense bottom layer of $\mathrm{CuCr}_{2} \mathrm{O}_{4}$ nanoparticles. During the multi-step heat-treatment from room temperature (RT) to $750{ }^{\circ} \mathrm{C}$ following the spray-coating, the polymer beads were decomposed, after which micro- and nanopores are expected to form, as shown schematically in Figure 1(a). 
For comparison, we also obtained Pyromark 2500 black paint (LA-CO) which is the state-of-the-art coating material for CSP solar towers. The Pyromark paint was diluted with additional solvents (xylene, and toluene), followed by the identical spray-coating, curing and annealing processes used for our black oxide samples.

\section{X-ray diffraction (XRD) analysis}

We carried out X-ray diffraction (XRD) analysis to investigate the crystal structure of copper iron manganese oxide $\left(\mathrm{CuFeMnO}_{4}\right)$ NPs, and copper chromate $\left(\mathrm{CuCr}_{2} \mathrm{O}_{4}\right)$ NPs. Crystal structures of the synthesized materials were characterized using a Bruker D2 Phaser XRD with $\mathrm{Cu} \mathrm{K}_{\alpha}(\lambda=0.154 \mathrm{~nm})$ as the radiation source. The scanning of $2 \theta$ angle (degree) was made in the range of $10^{\circ}-80^{\circ}$ with a scanning rate of $\sim 0.0406 \mathrm{deg} / \mathrm{step}$ and $1 \mathrm{step} / \mathrm{second}$.

\section{Scanning electron microscopy (SEM) and Focused Ion Beam (FIB)}

SEM (Oxford, acceleration voltage of $10 \mathrm{kV}$ ) was used to image the shapes of $\mathrm{CuFeMnO}_{4}$ and $\mathrm{CuCr}_{2} \mathrm{O}_{4}$ NPs, and the morphology of the top surface of the black oxide samples. For crosssectional imaging, FIB (SciosTM, FEI Company) sectioning was employed prior to SEM imaging.

\section{Visible/infrared (IR) reflectance measurement system}

An integration sphere (4" LabSphere ${ }^{\circledR}$, Spectraflect ${ }^{\circledR}$ coated) was assembled with an Andor ${ }^{\circledR}$ Shamrock $303 \mathrm{i}$ spectrometer which was equipped with $\mathrm{Si}$ and InGaAs-based detectors for visible/IR reflectance measurement. An incidence angle of $12.5^{\circ}$ was applied to measure the optical reflectance of prepared solar absorbing samples in the spectral range of 300-2000 nm at room temperature. The integration sphere was used to collect all angles of reflectance. 


\section{Figure of Merit (FOM)}

The figure of merit (FOM) value was evaluated with the measured reflectance data to compare the conversion efficiency of solar to thermal energy of solar absorbing layers used for solar receivers, and is defined as [21]:

$$
F O M=\frac{\int_{0}^{\infty}(1-R(\lambda)) I(\lambda) d \lambda-\frac{1}{C}\left[\int_{0}^{\infty}(1-R(\lambda)) B(\lambda, T) d \lambda\right]}{\int_{0}^{\infty} I(\lambda) d \lambda}
$$

where $R(\lambda)$ is the spectral reflectivity, $I(\lambda)$ is the spectral solar irradiance per unit area as defined by the reference solar spectral irradiation(ASTM G173), $B(\lambda, T)$ is the spectral thermal emissive power of a black body at temperature $T$, and $C$ is the solar concentration ratio. In this work, the FOM values were calculated by assuming $T=750{ }^{\circ} \mathrm{C}$ and $C=1000$ which are the conditions of high-temperature CSP plants. We also used wavelength ranging from $300 \mathrm{~nm}$ to $20 \mu \mathrm{m}$ to calculate the FOM value and the reflectance measured at $2 \mu \mathrm{m}$ is extrapolated to be the reflectance in the IR spectrum from 2 to $20 \mu \mathrm{m}$. For systems with a large solar concentration ratio $C$, such as solar towers that typically have $C$ 's greater than 1,000 , the optical absorption (related to optical reflectance properties) within the solar spectrum the overwhelmingly dominates the FOM values, so it is reasonable to extrapolate the reflectance data beyond $2 \mu \mathrm{m}$.

\section{Thermal endurance evaluation}

Thermal endurance of the fabricated black oxide layers was evaluated with thermal tests in air. Isothermal tests at $750{ }^{\circ} \mathrm{C}$ in air for $500 \mathrm{~h}$ were carried out for the tandem-structured samples of 
$\mathrm{CuFeMnO}_{4}(\mathrm{PT}) / \mathrm{CuCr}_{2} \mathrm{O}_{4}(\mathrm{DB})$. Additionally, 100 cycles of rapid thermal cycling from $\mathrm{RT}$ to $750{ }^{\circ} \mathrm{C}$ were carried out with a temperature ramping rate of $\pm 150{ }^{\circ} \mathrm{C} / \mathrm{min}$ on the black oxide samples as well as the Pyromark samples. FOM endurance was evaluated with following equations after the thermal annealing and cycling tests:

$$
\begin{gathered}
\text { Isothermal FOM endurance }=\frac{\operatorname{FOM}\left(t=500 h ; 750^{\circ} \mathrm{C}\right)}{\operatorname{FOM}\left(t=0 h ; 750^{\circ} \mathrm{C}\right)} \\
\text { Thermal cycling FOM endurance }=\frac{\operatorname{FOM}\left(n=100 ; 25 \text { to } 750^{\circ} \mathrm{C}\right)}{\operatorname{FOM}\left(n=1 ; 25 \text { to } 750^{\circ} \mathrm{C}\right)}
\end{gathered}
$$

\section{Results and discussion}

\section{Materials characterization}

The crystal structures of Cu-alloyed black oxide nanoparticles are analyzed with XRD as shown in Figure 2. As-prepared $\mathrm{CuCr}_{2} \mathrm{O}_{4}$ particles have a main plane (211) at $2 \theta=35.19^{\circ}$ and have a tetragonal crystal system with body-centered lattice [22-23]. After the rapid thermal cycling (RT$750{ }^{\circ} \mathrm{C} / 100$ cycles $)$ and isothermal annealing $\left(750{ }^{\circ} \mathrm{C} / 500 \mathrm{~h}\right)$ in air, the particles retain the original $\mathrm{CuCr}_{2} \mathrm{O}_{4}$ crystal structure and their particle size increases due to the sintering at high temperature, as illustrated in Figure 2(a). Based on this $\mathrm{XRD}$ analysis, $\mathrm{CuCr}_{2} \mathrm{O}_{4}$ nanoparticles are thermally stable at $750{ }^{\circ} \mathrm{C}$ in air because there is no obvious new phase appearing after the thermal tests. Similarly, crystal structures of $\mathrm{CuFeMnO}_{4}$ are confirmed by XRD analysis, as shown in Figure 2(b). As-prepared $\mathrm{CuFeMnO}_{4}$ particles have a main plane (311) at $2 \theta=35.6^{\circ}$ and are made of a cubic crystal system with a space group of Fd-3m, which matches well with the reported XRD data [24]. These $\mathrm{CuFeMnO}_{4}$ nanoparticles are also proved to be stable at 750 
${ }^{\circ} \mathrm{C}$ in air after the same thermal tests as to $\mathrm{CuCr}_{2} \mathrm{O}_{4}$ nanoparticles.

\section{Optimization of atomic composition and crystallization temperature}

As mentioned earlier, we have synthesized two types of copper chromate nanoparticles with atomic ratios of $1: 1$ and 1:2 between $\mathrm{Cu}$ and $\mathrm{Cr}$, respectively. Each type of the materials is subsequently crystallized at $550{ }^{\circ} \mathrm{C}$ for $5 \mathrm{~h}$ or $750{ }^{\circ} \mathrm{C}$ for $2 \mathrm{~h}$, both in air, as the final step of the synthesis. Figure 3 shows the SEM images of the copper chromates syntehsized under these four different conditions. Copper chromates crystallized at $550{ }^{\circ} \mathrm{C}$ possess particles smaller than 50 $\mathrm{nm}$, for both $1: 1$ and $1: 2 \mathrm{Cu} / \mathrm{Cr}$ ratios. When crystallized at $750{ }^{\circ} \mathrm{C}$, copper chromate with $1: 1$ $\mathrm{Cu} / \mathrm{Cr}$ ratio has particle sizes ranging from 200-600 nm (Figure 3(b)), whereas that with 1:2 $\mathrm{Cu} / \mathrm{Cr}$ ratio grows to larger sizes $(300 \mathrm{~nm}-1 \mu \mathrm{m}$ ), as shown in Figure 3(d). Figure 3(e) shows the spectral reflectance and FOM values of dense coating samples fabricated with the four different copper chromate particles. The figure shows that $\mathrm{CuCr}$ particles with a higher $\mathrm{Cr}$ content and lower crystallization temperature $\left(550^{\circ} \mathrm{C}\right)$ possess the lower reflectance and the higher FOM value (0.892). Therefore, $\mathrm{CuCr}_{2} \mathrm{O}_{4}$ crystallized at $550{ }^{\circ} \mathrm{C}$ is selected for further processing into the tandem structure. Our results are consistent with prior observations that $\mathrm{CuCr}_{2} \mathrm{O}_{4}$ has lower reflectance in the visible and NIR range compared to $\mathrm{CuCrO}_{4}[25,26]$ and the lower crystallization temperature leads to smaller $\mathrm{Cu}$ chromate particles [27].

Similar composition and crystallization temperature optimizations are applied to $\mathrm{Cu}-\mathrm{Fe}$ Mn oxide particles. Based on our results from the copper chromates, we kept the crystallization temperature constant at $550{ }^{\circ} \mathrm{C}$ for $\mathrm{Cu}-\mathrm{Fe}-\mathrm{Mn}$ oxides. This temperature resulted in similar particle size of 100-200 nm (Fig. 4(a)) for different compositions. We then optimized the material composition, namely, $\mathrm{Cu} / \mathrm{Fe} / \mathrm{Mn}$ atomic ratios. The main reasoning why we adjusted the 
relative amount of $\mathrm{Fe}$ and $\mathrm{Mn}$ atoms is to effectively control the spectral reflectance. We have chosen the $\mathrm{Cu}-\mathrm{Fe}-\mathrm{Mn}$ oxides due to its strong absorption in the visible and near-IR spectrum. Figure 4(b) shows reflectance data and FOM values of dense coating layers made of $\mathrm{Cu}-\mathrm{Fe}-\mathrm{Mn}$ oxide nanoparticles having five different atomic compositions of $\mathrm{Cu} / \mathrm{Fe} / \mathrm{Mn}$, among which $\mathrm{Cu} / \mathrm{Fe} / \mathrm{Mn}=1 / 1 / 1$ exhibits the highest FOM (0.881). From this experiment, some useful trends can be obtained with regard to optical properties change of coating layers with atomic compositions: in $\mathrm{Cu}-\mathrm{Fe}-\mathrm{Mn}$ oxides, a larger amount of $\mathrm{Fe}$ (e.g., $\mathrm{Cu} / \mathrm{Fe} / \mathrm{Mn}=0.5 / 2.0 / 0.5$ ) increases the reflectance in the NIR spectrum $(>750 \mathrm{~nm})$, and a larger amount of $\mathrm{Cu}$ (e.g., $\mathrm{Cu} / \mathrm{Fe} / \mathrm{Mn}=2.0 / 0.5 / 0.5)$ increases the reflectance in the visible and NIR spectrum, whereas a larger amount of $\mathrm{Mn}$ (e.g., $\mathrm{Cu} / \mathrm{Fe} / \mathrm{Mn}=0.5 / 0.5 / 2.0)$ only slightly increases the reflectance compared to the optimal composition of 1/1/1.

\section{Tandem-structured solar absorbing layers with a porous top layer}

Having identified the optimal compositions and crystallization temperatures (e.g., $\mathrm{CuCr}_{2} \mathrm{O}_{4}$ and $\mathrm{CuFeMnO}_{4}$, both crystallized at $550{ }^{\circ} \mathrm{C}$ ), we seek to further reduce the reflectance in the solar spectrum. First, using synthesized $\mathrm{CuFeMnO}_{4}$ nanoparticles, we introduce porous layers (Figure S1(b)) by using sacrificial polymer beads as described in the experimental section. Figure 5 shows that a porous layer of $\mathrm{CuFeMnO}_{4}$ particles has lower reflectance than a dense layer of $\mathrm{CuFeMnO}_{4}$ particles. Second, by comparing the spectral reflectance data of $\mathrm{CuCr}_{2} \mathrm{O}_{4}(\mathrm{DS})$ and $\mathrm{CuFeMnO}_{4}$ (DS) shown in Figure 5, one can see that the $\mathrm{CuCr}_{2} \mathrm{O}_{4}$ exhibits a peak in the reflectance at around $1 \mu \mathrm{m}$, while $\mathrm{CuFeMnO}_{4}$ shows an increasing reflectance above $\sim 1.1 \mu \mathrm{m}$. Therefore, by making tandem structures that combine the light absorption capabilities of both 
materials, one can anticipate a lower overall reflectance. Indeed, tandem structures with a porous top layer of $\mathrm{CuFeMnO}_{4}(\mathrm{PT})$ and a dense bottom layer of $\mathrm{CuCr}_{2} \mathrm{O}_{4}(\mathrm{DB})$ possess a low reflectance across the wide spectrum from $300 \mathrm{~nm}$ to $\sim 1.6 \mu \mathrm{m}$, leading to the highest FOM value (0.902) amongst all the samples.

The higher FOM in the tandem structure can be a result of three effects: i) combined light absorbing capabilities of $\mathrm{CuCr}_{2} \mathrm{O}_{4}$ and $\mathrm{CuFeMnO}_{4}$, as discussed above; ii) the gradation of refractive index and light trapping caused by the porous top and dense bottom structures; iii) larger overall thickness (5um PT and 25um DB layers in the tandem structure vs. 5um porous or 25um dense single layers). It is plausible that the graded refractive index could help lower the reflectance further. The top CFM layer with the porous structure has an effective refractive index closer to that of air, which leads to the reflection from the surface as well as light trapping effect by increasing the light path, and also the tandem structure induced a gradual change in the refractive index from the air to the Inconel substrate. Consequently, our tandem structure with a porous top layer yields a reduction in the Fresnel reflection over the broad spectral range (up to $\sim 2 \mu \mathrm{m})$. Fig. 5 also suggests that the bottom $\mathrm{CuCr}_{2} \mathrm{O}_{4}$ layer in the tandem structure also contributes to the light absorption within almost the entire spectral range, i.e., from $\sim 300 \mathrm{~nm}$ to $\sim 1.6 \mu \mathrm{m}$, thereby reducing the reflectance of the porous single (PS) layer (red curve). This suggests that the top 5um PT CFM layer is perhaps not optically thick within this spectral range. However, we can ensure that the bottom 25um-thick $\mathrm{CuCr}$ layer is optically thick, based on its optical absorption coefficient ( $\alpha=100-300 \mathrm{~mm}^{-1}$ or penetration depth $\sim 10-30 \mu \mathrm{m}$ [28]). Therefore, the lowered reflectance at the wavelengths $(<1.6 \mu \mathrm{m})$ originates from the combined light capabilities of two materials, rather than the increased thickness since the 25 um-thick bottom layer is already optically thick. Above $1.6 \mu \mathrm{m}$, the tandem structure shows a higher reflectance 
than the single layers made of $\mathrm{CuCr}_{2} \mathrm{O}_{4}$ and does not follow the ultralow reflectance of the bottom $\mathrm{CuCr}_{2} \mathrm{O}_{4}$ layer. This suggests that the 5um-thick PT CFM layer is already optically thick, and the reflectance is likely caused at the air/CFM interface, presumably because the light trapping in the porous structure is not as effective at long wavelength.

Figure 6 depicts the cross-sectional images observed with the FIB-assisted SEM analysis, showing that a porous layer of $\mathrm{CuFeMnO}_{4}$ particles with $\sim 5 \mu \mathrm{m}$ thickness is coated on a dense bottom layer. The porous top layer consists of micro-pores $(1-2 \mu \mathrm{m})$ and nano-pores (100-500 $\mathrm{nm})$, as expected from the design shown in Figure 1(a) and the sizes of polymer beads (1.3 $\mu \mathrm{m}$ and $400 \mathrm{~nm}$ ). The bottom layer of $\mathrm{CuCr}_{2} \mathrm{O}_{4}$ particles contains only nano-pores formed during solvent evaporation, as shown in the right images of Figure 6. For comparison, the left images in Figure 6, obtained from a sample consisting of a single dense layer of $\mathrm{CuFeMnO}_{4}$ particles and shows that there are nano-pores throughout the entire layer thickness. And also the effectiveness of the tandem structure is further demonstrated by the lower FOM values observed in single porous layers made of mixture of $\mathrm{CuFeMnO}_{4}$ and $\mathrm{CuCr}_{2} \mathrm{O}_{4}$ nanoparticles (Figure S2).

\section{FOM endurance by isothermal and thermal cycling tests}

After annealing the sample at $750{ }^{\circ} \mathrm{C}$ in air for $500 \mathrm{~h}$, the $\mathrm{CuFeMnO}_{4}(\mathrm{PT}) / \mathrm{CuCr}_{2} \mathrm{O}_{4}(\mathrm{DB})$ sample shows a slight increase in the reflectance within a wide spectrum including visible and near-IR (Figure 7(a)). The porous surface morphology with nano-scaled pores and micro-scaled pores

can be degraded at high temperature $\left(750{ }^{\circ} \mathrm{C}\right)$ for $500 \mathrm{~h}$, which can result in the increase of reflectance in wide spectrum. In $\mathrm{CuFeMnO}_{4}(\mathrm{PT}) / \mathrm{CuCr}_{2} \mathrm{O}_{4}(\mathrm{DB})$ sample, $1 \mu \mathrm{m}$ peak emerged 
after isothermal annealing at $750^{\circ} \mathrm{C}$. Apart from the degradation of porous structure, another possible reason for this new $1 \mu \mathrm{m}$ reflectance peak may result from the new phase formation of $\mathrm{CuO}$ after a long time annealing at high temperature, because the coating layer made of $\mathrm{CuO}$ NPs (purchased from Sigma-Aldrich, US) increases reflectance in near-IR spectrum from 800 $\mathrm{nm}$ wavelength, as shown in Figure S3. The fundamental reason of $1 \mu \mathrm{m}$ reflectance peak has to be studied in future research. $\mathrm{CuFeMnO}_{4}(\mathrm{PT}) / \mathrm{CuCr}_{2} \mathrm{O}_{4}(\mathrm{DB})$ sample has $\mathrm{FOM}$ value of 0.903 in as-prepared state which is regarded as the best conversion efficiency of solar to thermal energy yet achieved for these conditions (temperature $=750{ }^{\circ} \mathrm{C}, \mathrm{C}=1000$, air) and it resists degradation (FOM of 0.896$)$ from thermal testing $\left(750{ }^{\circ} \mathrm{C}\right.$ for $500 \mathrm{~h}$ under air environment). After the isothermal test, this tandem-structured solar absorbing samples show an FOM endurance of 0.992 which can be evaluated with Equation (2). After the isothermal annealing at $750^{\circ} \mathrm{C} / 500 \mathrm{~h} / \mathrm{air}$, the porous surface morphology is seen to be preserved except for moderate particle growth (Figure 8(a-1) and (a-2)). Particle and crystal growth can reduce the degree of multi-scaled surface morphology, which will increase reflectance and lower the FOM values.

In rapid thermal cycling tests $\left(\mathrm{RT}-750{ }^{\circ} \mathrm{C} / 100\right.$ cycles), Figure $7(\mathrm{~b})$ shows both $\mathrm{CuFeMnO}_{4}(\mathrm{PT}) / \mathrm{CuCr}_{2} \mathrm{O}_{4}(\mathrm{DB})$ sample and Pyromark sample has similar behaviors in that reflectance increases in visible spectrum and decreases in near-IR spectrum longer than $1 \mu \mathrm{m}$ after thermal testing. The reflectance increase in the visible portion of the spectrum can be explained by the reduction of surface nano-pores by high temperature particle growth and sintering. However, dominant factors affecting the reflectance decrease in near-IR above $1 \mu \mathrm{m}$ have to be studied in more detail in future research, as the reflectance behavior in near-IR spectrum above $1 \mu \mathrm{m}$ differs from the results of isothermal tests observed in Figure 7(a). Compared to the lab-coated Pyromark sample which has FOM of 0.8968 after 1 cycle and FOM 
endurance of 0.9987 after 100 cycles calculated by Equation (3), $\mathrm{CuFeMnO}_{4}(\mathrm{PT}) / \mathrm{CuCr}_{2} \mathrm{O}_{4}(\mathrm{DB})$ sample reaches the higher FOM of 0.902 and better FOM endurance of 0.9993 after 100 cycles. As shown in in Figure 7(c), the tandem-structured sample kept the black surface color by high light absorption after the 100-cycle annealing, whereas the lab-coated Pyromark sample turned brownish after 1 cycle and 100 cycles because of the higher reflectance at wavelength above 600 nm. Figure 8(b-1) and (b-2) show that the porous surface morphology of $\mathrm{CuFeMnO}_{4}$ layer coated on the dense $\mathrm{CuCr}_{2} \mathrm{O}_{4}$ layer is preserved to be almost indistinguishable to 1-cycled samples in miro-scaled image after the thermal cycling tests. Nano-scaled morphology change needs to be studied in future research to analyze the effect of morphology change on reflectance through thermal tests. When evaluating the porous structure based on these SEM images, lab-coated Pyromark sample has a much denser surface structure than $\mathrm{CuFeMnO}_{4}(\mathrm{PT}) / \mathrm{CuCr}_{2} \mathrm{O}_{4}(\mathrm{DB})$ samples, as compared in Figure 8. Lab-coated Pyromark sample contains only very small nanopores on surface which cannot decrease reflectance in a wide spectral range including visible and near-IR. Furthermore, the porous surface structure of our tandem layers is more effective to accommodate volume change during a rapid temperature change, which can prevent micro-cracks and delamination after many thermal cycles.

For high temperature application in air, there could be a concern of oxidation of the substrate (Inconel) and/or element diffusion between the black oxide and the Inconel. The preserved high FOM and no sign of delamination after thermal cycling (100 cycles) and thermal annealing (500 hours at $750^{\circ} \mathrm{C}$ ) suggest that the Inconel is stable within the experimental conditions tested in this study. It is known that Inconel 625 can form a protective layer upon oxidation, which prevents further damage to the material [29]. It has been shown that Inconel 625 is stable in environments less than $900^{\circ} \mathrm{C}$ and spinel oxide coatings (such as $\mathrm{CuCr}_{2} \mathrm{O}_{4}$ ) can be used to block diffusion and 
oxidation of $\mathrm{Cr}$ (in the Inconel substrate) [30]. Therefore, we believe Inconel 625 to be a suitable substrate for our high temperature application at $750^{\circ} \mathrm{C}$. However, testing for a period substantially longer than 500 hours needs to be carried out in order to fully evaluate its suitability for 30-year service in future high-temperature CSP plants.

The lack of delamination suggests that the coefficient of thermal expansion (CTE) mismatch between the top and bottom layer is important. CTE of the substrate is about $16 \mathrm{ppm} / \mathrm{K}$ between between $25^{\circ} \mathrm{C}-800^{\circ} \mathrm{C}$ [31]. The coating is made of spinel oxides plus a very small amount of spin-on glass (methyl phenyl polysiloxane). The spinel oxides have CTE values ranging from 7$12 \mathrm{ppm} / \mathrm{K}$ [32] and the spin-on glass generally has a high CTE greater than $12 \mathrm{ppm} / \mathrm{K}$ [33], so the CTE of the coating will be slightly higher than 7-12 ppm/K. However, the coating has a porous structure (even in the 'dense' layers, as shown in Fig. 6), so it can accommodate thermal stress caused by the potential CTE mismatch. We believe this could be an important reason for the excellent adhesion shown in our samples.

\section{Conclusion}

Two types of black oxide nanoparticles were synthesized including $\mathrm{Cu}-\mathrm{Fe}-\mathrm{Mn}$ oxides and $\mathrm{Cu}-\mathrm{Cr}$ oxides, and their compositions and crystallization conditions were optimized based on the reflectance data and FOM evaluations. Utilizing these nanoparticles, 2-layered tandem structure of solar absorbing layer was devised with a porous $\mathrm{CuFeMnO}_{4}$ top layer and a dense $\mathrm{CuCr}_{2} \mathrm{O}_{4}$ bottom layer. These layers were chosen to have complementary absorption in the visible and infrared regions. The tandem structure showed an excellent FOM value (0.903), indicating 90.3\% solar to thermal conversion efficiency. This exceeds that of an solar absorbing layer made with a commercial Pyromark black paint. From FOM thermal endurance tests, 2-layered 
$\mathrm{CuFeMnO}_{4}(\mathrm{PT}) / \mathrm{CuCr}_{2} \mathrm{O}_{4}(\mathrm{DB})$ solar absorbing sample shows FOM endurance above 0.99 after $750{ }^{\circ} \mathrm{C} / 500 \mathrm{~h}$ in air. This tandem-structured solar absorbing layer with excellent FOMs and thermal endurance can be used for the cost-competitive next generation concentrating solar power plants.

\section{Acknowledgement}

The support of this research by Department of Energy through DOE SunShot Project (DEEE0005802) is acknowledged.

\section{References}

[1] J. A. Turner, Science 285 (1999) 687-689.

[2] Varun, I. K. Bhat, R. Prakash, Renewable and Sustainable Energy Reviews 13 (2009) 10671073.

[3] J. Khamwannah, Y. Zhang, S. Y. Noh, H. Kim, C. Frandsen, S. D. Kong, S. Jin, Nano Energy 1 (2012) 411-417.

[4] C. K. Ho, B. D. Iverson, Renewable and Sustainable Energy Reviews 29 (2014) 835-846.

[5] B. Hayman, J. Wedel-Heinen, P. Brøndsted, MRS Bulletin 33 (2008) 343-353.

[6] Levelized Cost and Levelized Avoided Cost of New Generation Resources, Annual Energy Outlook 2014, US Energy Information Administration (EIA), DOE/EIA-0383ER, 2014. 
[7] Tackling Challenges in Solar, 2014 SunShot Initiative Portfolio, US Department of Energy, DOE/EE-1081, 2014.

[8] J. J. Burhardt III, G. A. Heath, C. S. Turchi, Environ. Sci. Technol. 45 (2011) 2457-2464.

[9] J. Moon, D. Lu, B. VanSaders, T. K. Kim, S. D. Kong, S. Jin, R. Chen, and Z. Liu, Nano Energy 8, (2014) 238-246.

[10] O. Behar, A. Khellaf, K. Mohammedi, Renewable and Sustainable Energy Reviews 23 (2013) 12-39.

[11] C. K. Ho, A. R. Mahoney, A. Ambrosini, M. Bencomo, A. Hall, T. N. Lambert, J. Solar Energy Engineering 136 (2014) 014502-1-014502-4.

[12] C. E. Kennedy, Review of Mid- to High-Temperature Solar Selective Absorber Materials, NREL/TP-520-31267, 2002.

[13] A. Ambrosini, T. N. Lambert, M. Bencomo, A. Hall, K. vanEvery, N. P. Siegel, C. K. Ho, Proceedings of the ASME $20115^{\text {th }}$ International Conference on Energy Sustainability, ES201154241, 2011

[14] J. Vince, A. Šurca Vuk, U. Opara Krašovec, B. Orel, M. Köhl, M. Heck, Solar Energy Materials and Solar Cells 79 (2003) 313-330.

[15] R. Bayon, G. San Vicente, C. Maffiotte, A. Morales, Renewable Energy 33 (2) (2008) 348353.

[16] K. Peng, Y. Xu, Y. Wu, Y. Yan, S. -T. Lee, J. Zhu, Small 1 (2005) 1062-1067. 
[17] L. Tsakalakos, J. Balch, J. Fronheiser, B. A. Korevaar, O. Sulima, J. Rand, Appl. Phys. Lett. 91 (2007) 233117-1-233117-3.

[18] J. Zhu,Y. Cui, Nat. Mater. 9 (2010) 183-184.

[19] M. D. Kelzenberg, S. W. Boettcher, J. A. Petykiewicz, D. B. Turner-Evans, M. C. Putnam, E. L. Warren, J. M. Spurgeon, R. M. Briggs, N. S. Lewis, H. A. Atwater, Nat. Mater. 9 (2010) 239-244.

[20] A. Kargar, S. Yavuz, T. K. Kim, C. H. Liu, C. Kuru, C. S. Rustomji, S. Jin, P. R. Bandaru, Appl. Mater. Interfaces 7 (2015) 17851-17856.

[21] J. Moon, T. K. Kim, B. VanSaders, C. Choi, Z. Liu, S. Jin, and R. Chen, Solar Energy Materials \& Solar Cells 134 (2015) 417-424.

[22] O. Crottaz, F. Kubel, H. Schmid, J. Mater. Chem. 7 (1997) 143-146.

[23] Y. G. Chukalkin, V. V. Petrov, V. R. Shtirs, B. Goshchitskii, Phys. Status Solidi A 92 (1985) $347-354$.

[24] S. Jogalekar, Indian J. Pure Appl. Phys. 5 (1967) 9-13.

[25] J. Liang, Q. Peng, X. Wang, Z. Xhang, R. Wang, X. Qiu, C. Nan, Y. Li, Inorg. Chem. 44 (2005) 9405-9415.

[26] V. Kocsis, S. Bordács, D. Varjas, K. Penc, A. Abouelsayed, C. A. Kuntscher, K. Ohgushi, Y. Tokura, and I. Kézsmárki, Phys. Rev. B 87 (2013) 064416.

[27] W. Yuan, X. Liu, L. Li, Appl. Surf. Sci. 319 (2014) 350-357.

[28] R. Levinson, P. Berdahl, H. Akbari, H, Solar Energy Materials \& Solar Cells 89 (2005) 351- 
389.

[29] L.-P. Lefebvre, J. Banhart, D. C. Dunand, Adv. Eng. Mater. 10 (2008) 775-787.

[30] Y. Wang., 2013, Structure and Electrical Conductivity of Mn-based Spinels Used as Solid Oxide Fuel Cell Interconnect Coatings (Master's thesis).

[31] Haynes data sheet, retrieved from https://www.haynesintl.com/pdf/h3073.pdf.

[32] A Petric and H Ling J. Am. Ceram. Soc. 90 (2007) 1515-1520.

[33] W. Oh and M.Ree, Langmuir 20 (2004) 6932-6939. 


\section{Figure Captions}

Figure 1. Concept diagrams showing the layer structure and its effect on optical reflectance of (a) the tandem-structured solar absorbing layer with a porous top layer coated on a dense bottom layer and (b) the single-layered solar absorbing sample with a dense layer. (IR: infrared spectrum, VIS: visible spectrum).

Figure 2. $\mathrm{XRD}$ analysis for (a) synthesized $\mathrm{CuCr}_{2} \mathrm{O}_{4}$ nanoparticles and (b) $\mathrm{CuFeMnO}_{4}$ nanoparticles in as-prepared state, after thermal cycling (RT-750 ${ }^{\circ} \mathrm{C} / 100$ cycles) in air, and after isothermal annealing at $750{ }^{\circ} \mathrm{C}$ for $500 \mathrm{~h}$ under air.

Figure 3. SEM images and reflectance measurement results of copper chromate nanoparticles synthesized with different conditions of atomic ratio of $\mathrm{Cu} / \mathrm{Cr}$ and crystallizing temperature; (a) $1 / 1$, and $550^{\circ} \mathrm{C} / 5 \mathrm{~h} /$ air, (b) $1 / 1$, and $750^{\circ} \mathrm{C} / 2 \mathrm{~h} /$ air, (c) $1 / 2,550^{\circ} \mathrm{C} / 5 \mathrm{~h} /$ air, and (d) $1 / 2,750^{\circ} \mathrm{C} / 2 \mathrm{~h} /$ air. (DS: a dense single layer coated without using pore-forming polymer beads).

Figure 4. (a) SEM images of $\mathrm{CuFeMnO}_{4}$ nanoparticles crystallized at $550^{\circ} \mathrm{C} / 5 \mathrm{~h}$, and (b) reflectance measurements of solar absorbing layers with a dense single layer composed of $\mathrm{Cu}$ Fe-Mn oxide nanoparticles having different atomic compositions.

Figure 5. Reflectance and FOM comparison amongst different solar absorbing layers; A dense single layer of $\mathrm{CuFeMnO}_{4} \mathrm{NPs}$ (blue line), a porous single layer of $\mathrm{CuFeMnO}_{4} \mathrm{NPs}$ (red line), a dense single layer of $\mathrm{CuCr}_{2} \mathrm{O}_{4}$ (green line), and two-layered tandem structure with a porous $\mathrm{CuFeMnO}_{4}$ top layer and a dense $\mathrm{CuCr}_{2} \mathrm{O}_{4}$ bottom layer (black line). (DS: a dense single layer, PS: a porous single layer, PT: a porous top layer, and DB: a dense bottom layer). 
Figure 6. Cross-sectional SEM images assisted with FIB slicing for 2-layered tandem structure of $\mathrm{CuFeMnO}_{4}(\mathrm{PT}) / \mathrm{CuCr}_{2} \mathrm{O}_{4}(\mathrm{DB})$ sample and a dense single-layered $\mathrm{CuFeMnO}_{4}$ sample. In red rectangular areas, the zoomed-in images were observed from top to lower space. (Black scale bars: $1.0 \mu \mathrm{m})$.

Figure 7. Reflectance measured from (a) isothermal tests $\left(750{ }^{\circ} \mathrm{C} / 500\right.$ h) for $\mathrm{CuFeMnO}_{4}(\mathrm{PT}) / \mathrm{CuCr}_{2} \mathrm{O}_{4}(\mathrm{DB})$ sample, and (b) thermal cycling test (RT-750 ${ }^{\circ} \mathrm{C} / 100$ cycles) for $\mathrm{CuFeMnO}_{4}(\mathrm{PT}) / \mathrm{CuCr}_{2} \mathrm{O}_{4}(\mathrm{DB})$ sample and lab-coated Pyromark sample, and (c) photo images taken from thermal cycling tests after 1 cycle and 100 cycles; (c-a) $\mathrm{CuFeMnO}_{4}(\mathrm{PT}) / \mathrm{CuCr}_{2} \mathrm{O}_{4}(\mathrm{DB})$, and (c-b) lab-coated Pyromark.

Figure 8. SEM images of surface morphologies obtained from isothermal tests at $750{ }^{\circ} \mathrm{C}$ for 500 $\mathrm{h}$ in air for $\mathrm{CuFeMnO}_{4}(\mathrm{PT}) / \mathrm{CuCr}_{2} \mathrm{O}_{4}(\mathrm{DB})$ solar absorbing samples ((a-1) and (a-2)), and the morphologies from the rapid thermal cycling tests $\left(\mathrm{RT}-750{ }^{\circ} \mathrm{C}\right)$ for $\mathrm{CuFeMnO}_{4}(\mathrm{PT}) / \mathrm{CuCr}_{2} \mathrm{O}_{4}(\mathrm{DB})$ samples ((b-1) and (b-2)) and lab-coated Pyromark samples ((c-1) and (c-2)). 
Figures

(a)

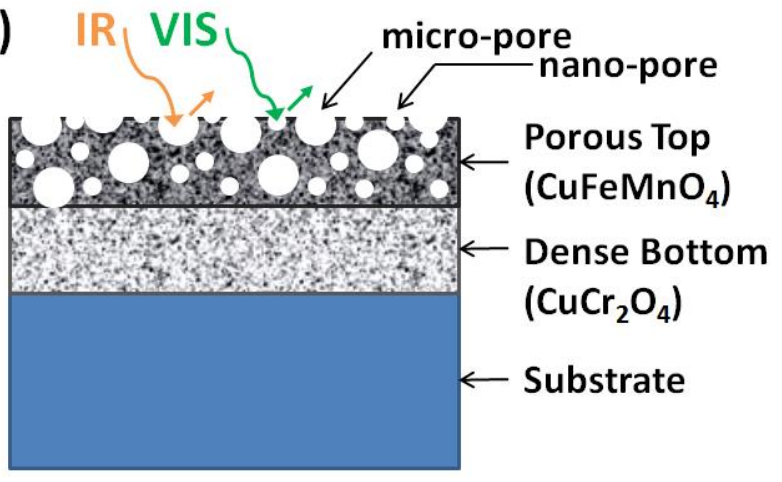

(b)

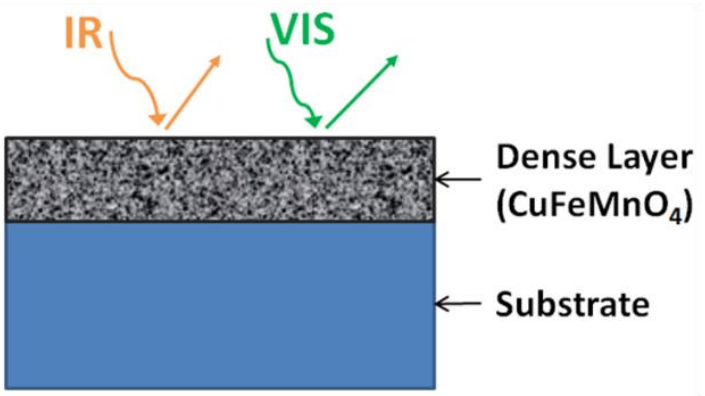

Figure 1. Concept diagrams showing the layer structure and its effect on optical reflectance of (a) the tandem-structured solar absorbing layer with a porous top layer coated on a dense bottom layer and (b) the single-layered solar absorbing sample with a dense layer. (IR: infrared spectrum, VIS: visible spectrum). 
(a)

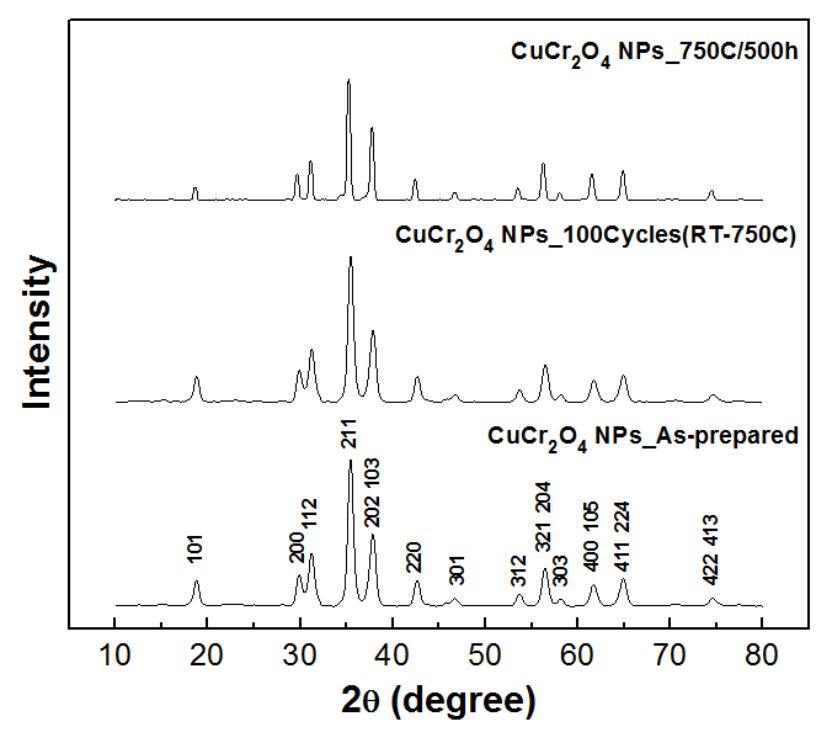

(b)

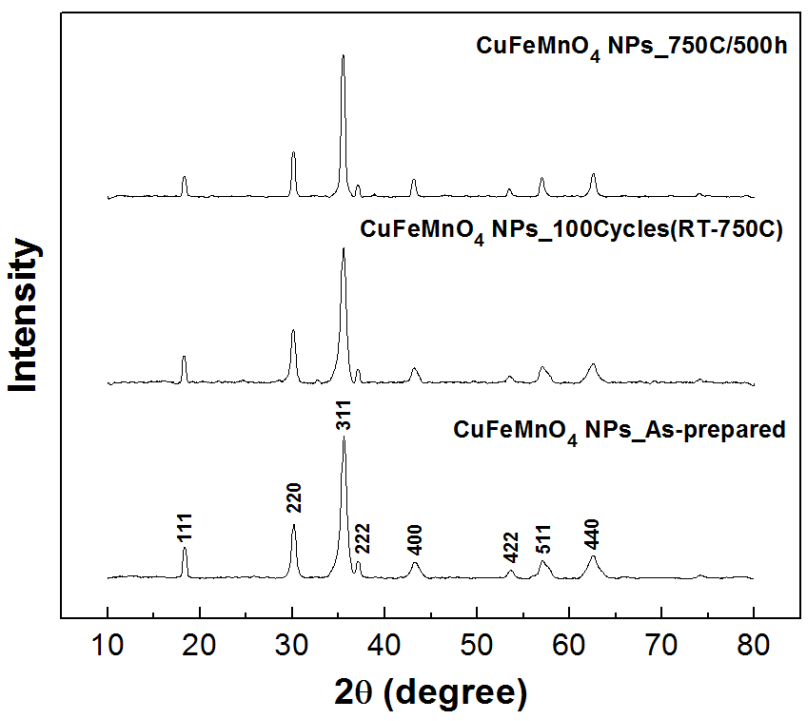

Figure 2. $\mathrm{XRD}$ analysis for (a) synthesized $\mathrm{CuCr}_{2} \mathrm{O}_{4}$ nanoparticles and (b) $\mathrm{CuFeMnO}_{4}$ nanoparticles in as-prepared state, after thermal cycling (RT-750 ${ }^{\circ} \mathrm{C} / 100$ cycles) in air, and after isothermal annealing at $750{ }^{\circ} \mathrm{C}$ for $500 \mathrm{~h}$ under air. 

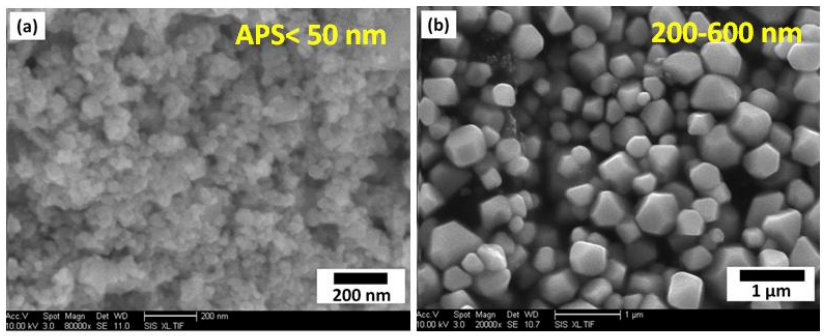

(e)
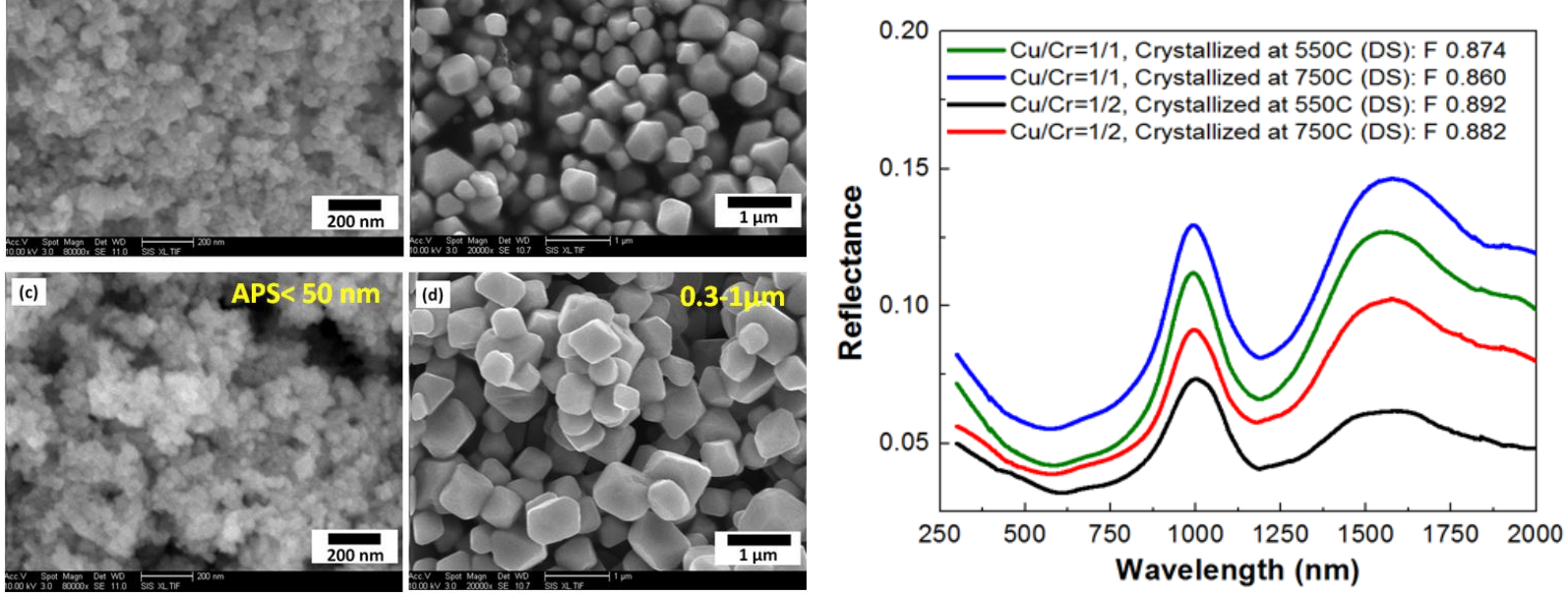

Figure 3. SEM images and reflectance measurement results of copper chromate nanoparticles synthesized with different conditions of atomic ratio of $\mathrm{Cu} / \mathrm{Cr}$ and crystallizing temperature; (a) $1 / 1$, and $550^{\circ} \mathrm{C} / 5 \mathrm{~h} /$ air, (b) $1 / 1$, and $750^{\circ} \mathrm{C} / 2 \mathrm{~h} /$ air, (c) $1 / 2,550^{\circ} \mathrm{C} / 5 \mathrm{~h} /$ air, and (d) $1 / 2,750^{\circ} \mathrm{C} / 2 \mathrm{~h} /$ air. (DS: a dense single layer coated without using pore-forming polymer beads). 

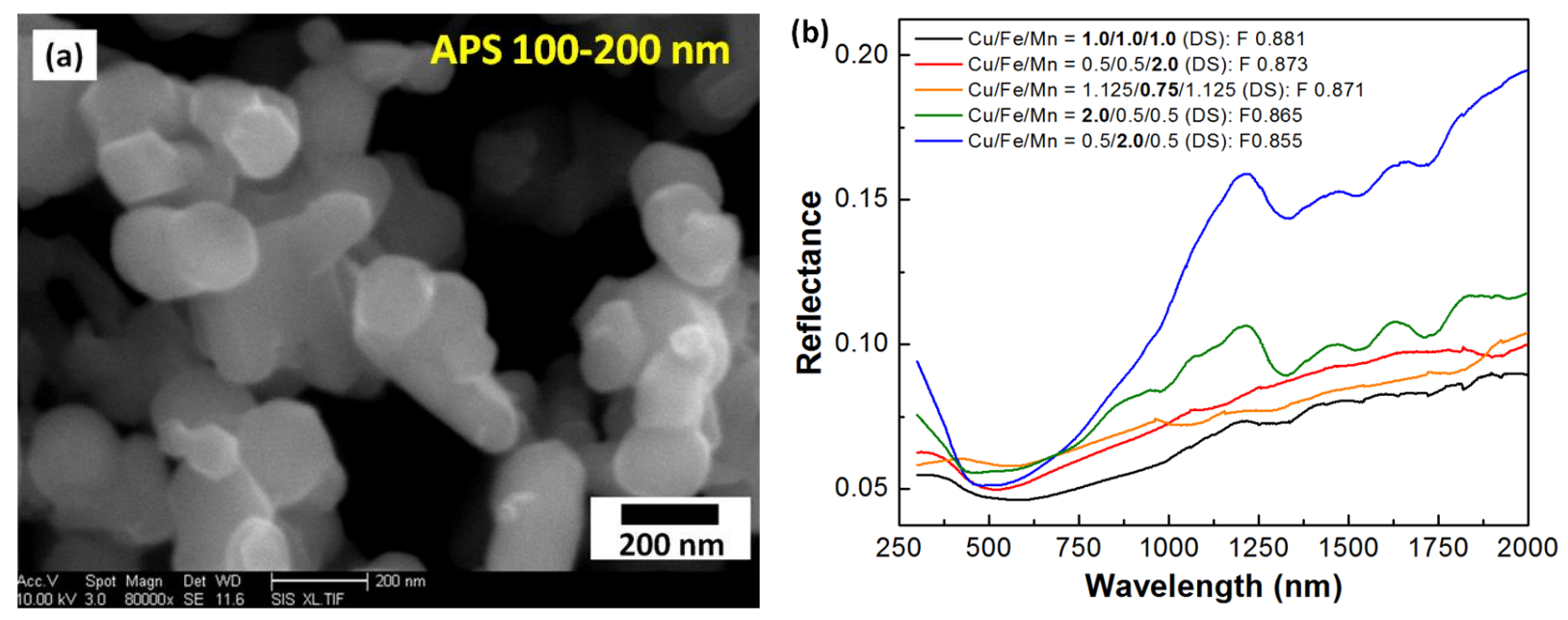

Figure 4. (a) SEM images of $\mathrm{CuFeMnO}_{4}$ nanoparticles crystallized at $550^{\circ} \mathrm{C} / 5 \mathrm{~h}$, and (b) reflectance measurements of solar absorbing layers with a dense single layer composed of $\mathrm{Cu}$ Fe-Mn oxide nanoparticles having different atomic compositions. 


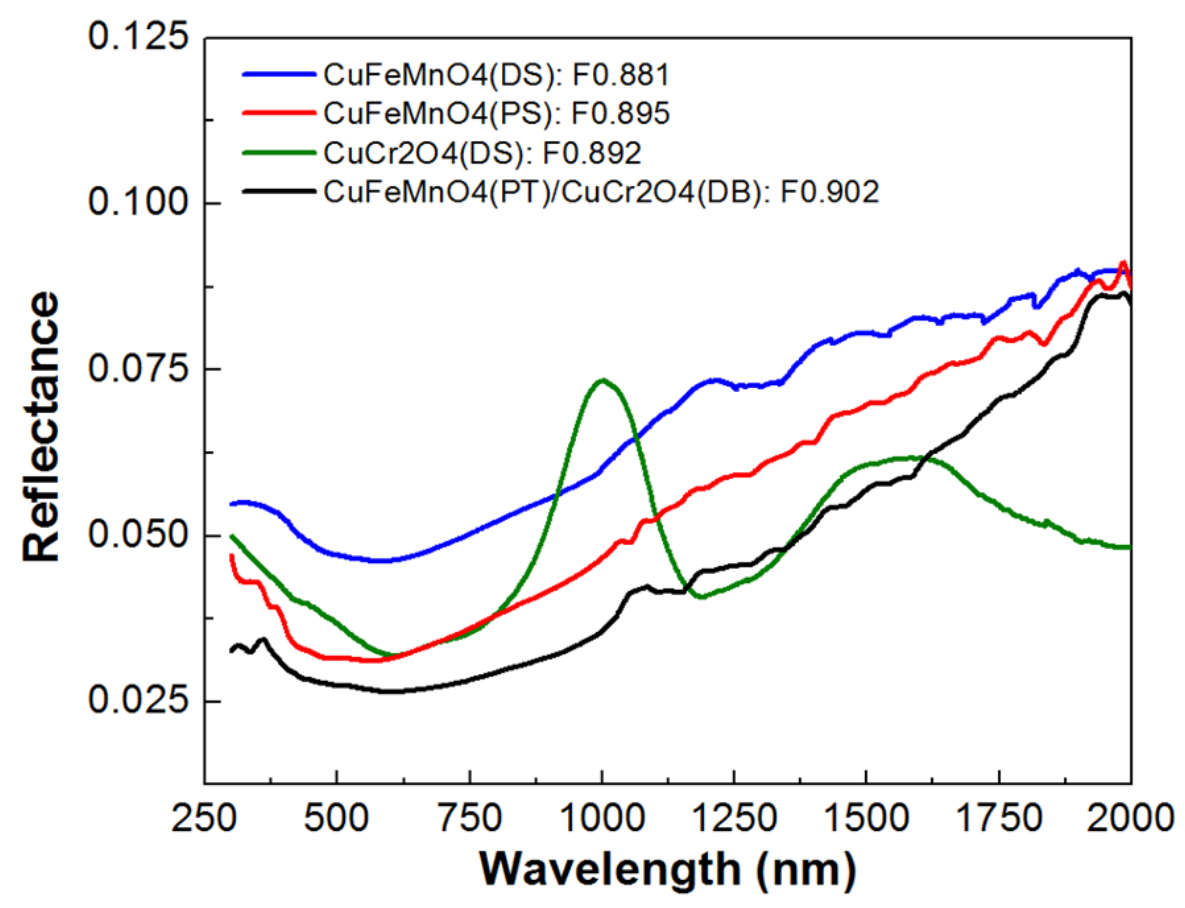

Figure 5. Reflectance and FOM comparison amongst different solar absorbing layers; A dense single layer of $\mathrm{CuFeMnO}_{4} \mathrm{NPs}$ (blue line), a porous single layer of $\mathrm{CuFeMnO}_{4} \mathrm{NPs}$ (red line), a dense single layer of $\mathrm{CuCr}_{2} \mathrm{O}_{4}$ (green line), and two-layered tandem structure with a porous $\mathrm{CuFeMnO}_{4}$ top layer and a dense $\mathrm{CuCr}_{2} \mathrm{O}_{4}$ bottom layer (black line). (DS: a dense single layer, PS: a porous single layer, PT: a porous top layer, and DB: a dense bottom layer). 

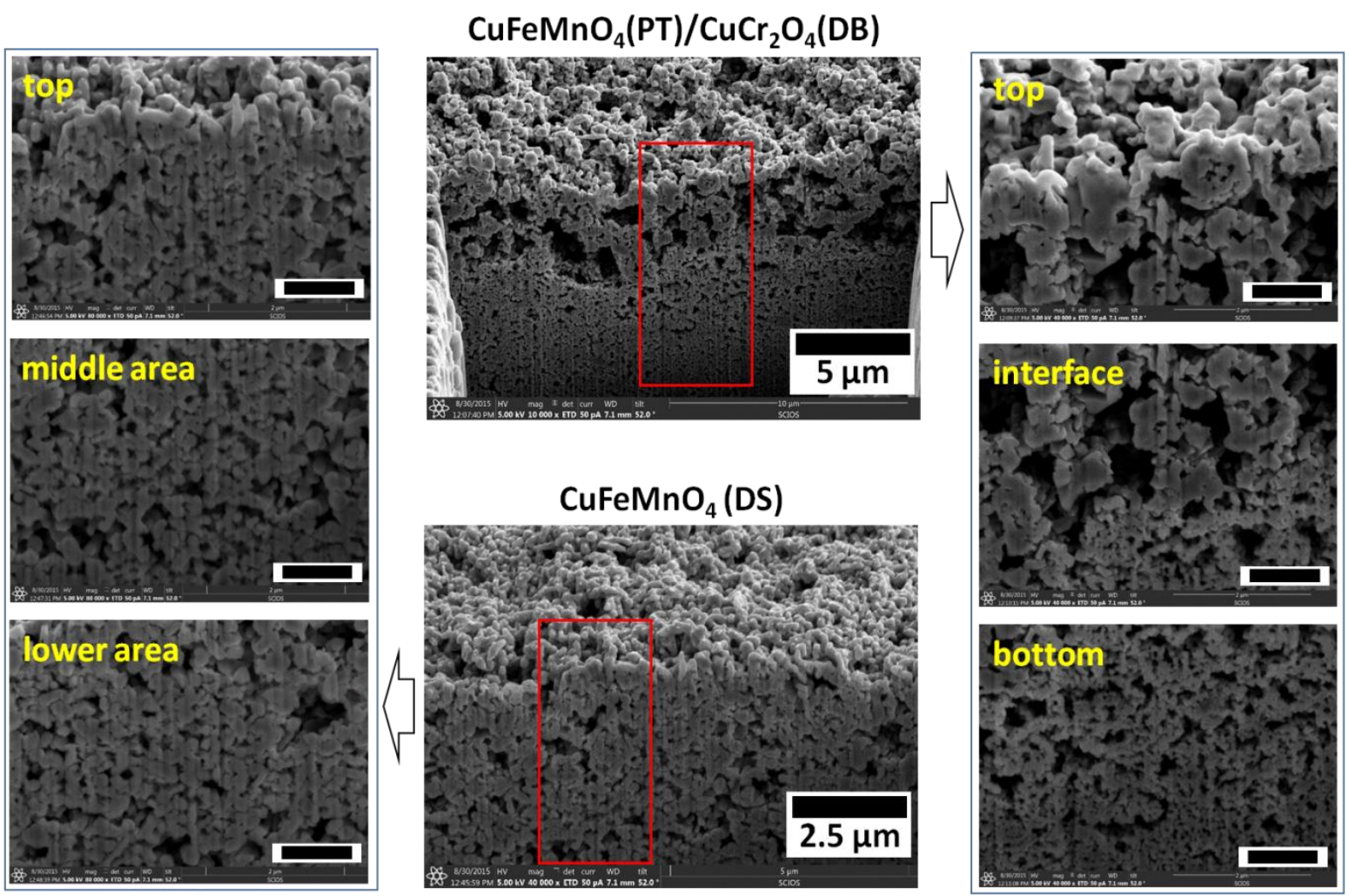

Figure 6. Cross-sectional SEM images assisted with FIB slicing for 2-layered tandem structure of $\mathrm{CuFeMnO}_{4}(\mathrm{PT}) / \mathrm{CuCr}_{2} \mathrm{O}_{4}(\mathrm{DB})$ sample and a dense single-layered $\mathrm{CuFeMnO}_{4}$ sample. In red rectangular areas, the zoomed-in images were observed from top to lower space. (Black scale bars: $1.0 \mu \mathrm{m})$. 
(a)

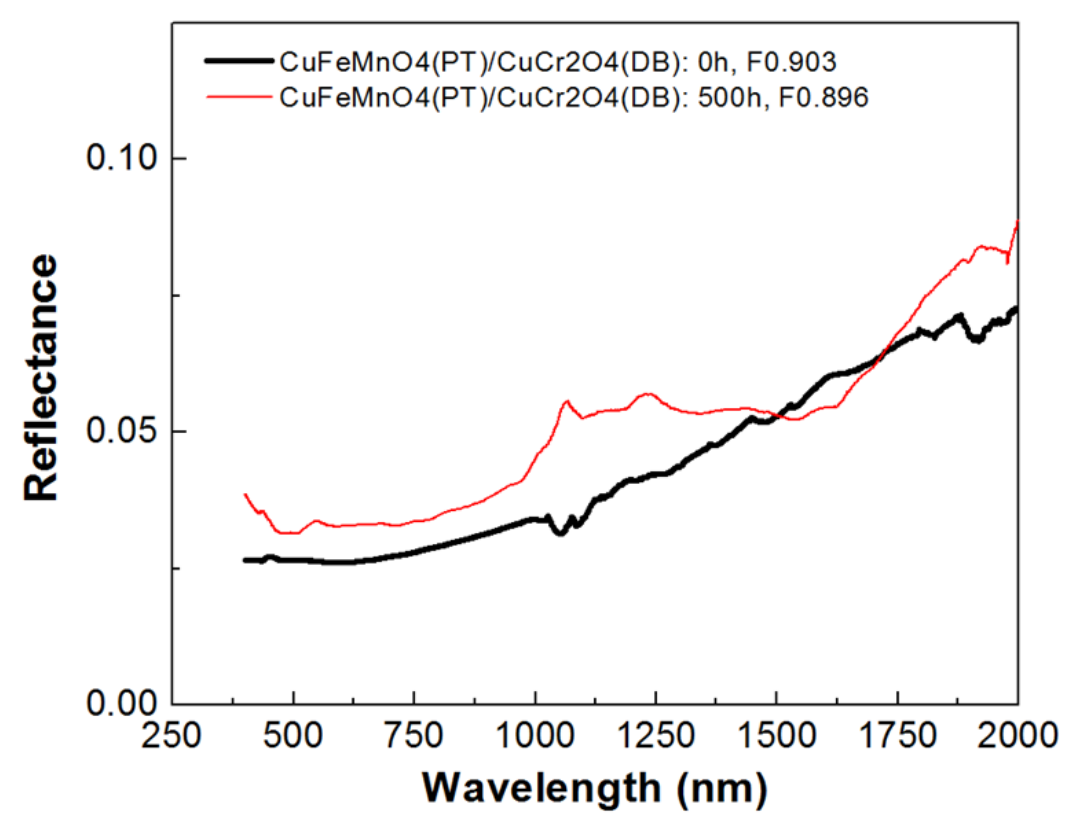

(b)

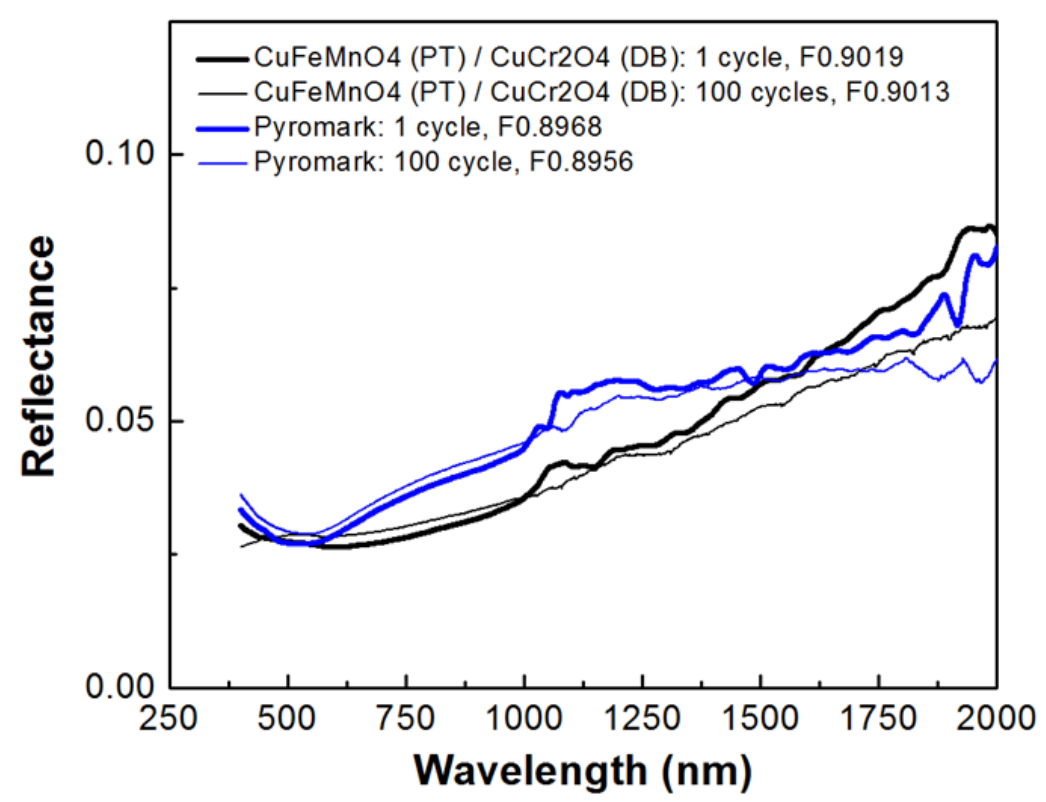


(c)

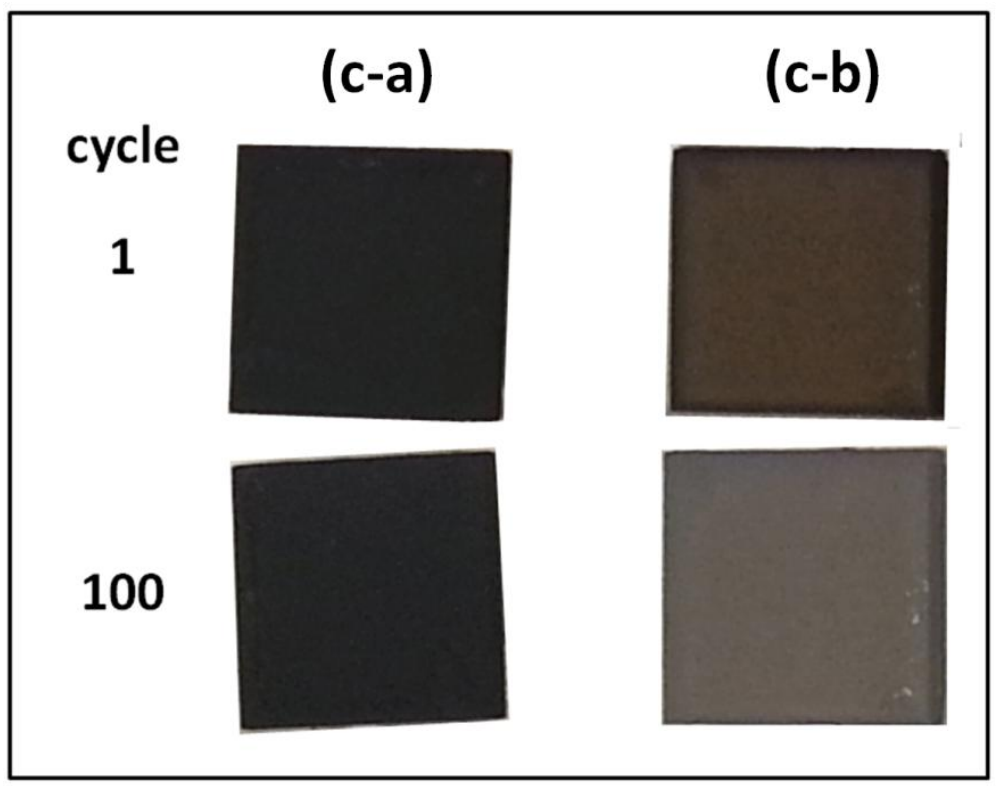

Figure 7. Reflectance measured from (a) isothermal tests $\left(750{ }^{\circ} \mathrm{C} / 500\right.$ h $)$ for $\mathrm{CuFeMnO}_{4}(\mathrm{PT}) / \mathrm{CuCr}_{2} \mathrm{O}_{4}(\mathrm{DB})$ sample, and (b) thermal cycling test (RT-750 ${ }^{\circ} \mathrm{C} / 100$ cycles) for $\mathrm{CuFeMnO}_{4}(\mathrm{PT}) / \mathrm{CuCr}_{2} \mathrm{O}_{4}(\mathrm{DB})$ sample and lab-coated Pyromark sample, and (c) photo images taken from thermal cycling tests after 1 cycle and 100 cycles; (c-a) $\mathrm{CuFeMnO}_{4}(\mathrm{PT}) / \mathrm{CuCr}_{2} \mathrm{O}_{4}(\mathrm{DB})$, and (c-b) lab-coated Pyromark. 

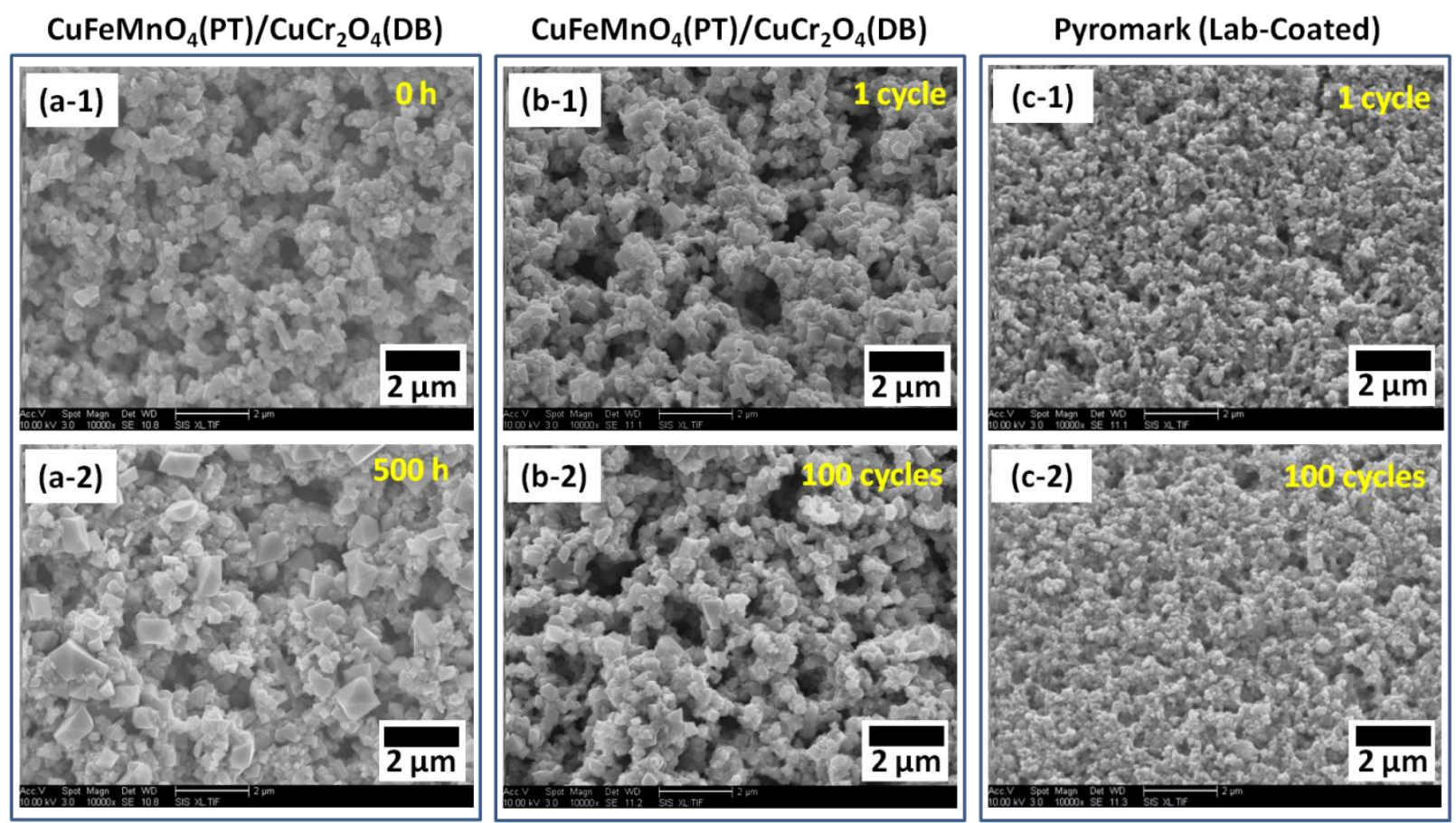

Figure 8. SEM images of surface morphologies obtained from isothermal tests at $750{ }^{\circ} \mathrm{C}$ for 500 $\mathrm{h}$ in air for $\mathrm{CuFeMnO}_{4}(\mathrm{PT}) / \mathrm{CuCr}_{2} \mathrm{O}_{4}(\mathrm{DB})$ solar absorbing samples ((a-1) and (a-2)), and the morphologies from the rapid thermal cycling tests $\left(\mathrm{RT}-750{ }^{\circ} \mathrm{C}\right)$ for $\mathrm{CuFeMnO}_{4}(\mathrm{PT}) / \mathrm{CuCr}_{2} \mathrm{O}_{4}(\mathrm{DB})$ samples ((b-1) and (b-2)) and lab-coated Pyromark samples ((c-1) and (c-2)). 